\title{
De núcleo de povoamento à praça de guerra: a Colônia do Sacramento de 1735 a 1777
}

\section{Paulo César Possamai}

A fundação da Colônia do Sacramento na margem norte do Rio da Prata conjugava os interesses dos comerciantes do Rio de Janeiro, interessados na retomada do intenso comércio com Buenos Aires existente na época da União Ibérica, assim como da Coroa portuguesa, que desejava expandir seus domínios até o Rio da Prata. Os principais elementos responsáveis pelo desenvolvimento da rede contrabandista eram os portugueses. A relativa proximidade do Prata com os portos brasileiros e a facilidade da obtenção de escravos em suas feitorias na África foram os principais fatores da preponderância comercial dos luso-brasileiros em Buenos Aires durante a União Ibérica. ${ }^{1}$ Essas vantagens levaram os portugueses a investir num entreposto no Prata.

Em 1677, o Príncipe Regente D. Pedro instruiu secretamente o tenente-general Jorge Soares de Macedo a visitar Paranaguá para determinar o valor de supostas minas e prata e de lá passar ao Rio da Prata, onde deveria erguer uma fortificação na ilha de São Gabriel. ${ }^{2}$ Macedo optou pela viagem marítima, mas o mau tempo fez malograr a expedição por três vezes. Entrementes D. Manuel Lobo foi escolhido por D. Pedro para comandar a nova fundação.

D. Manuel Lobo tomou posse do governo do Rio de Janeiro em 9 de maio de 1679, dando logo início à preparação da expedição que viria a fundar uma fortaleza às margens do Rio da Prata. Em janeiro de 1680, D. Manuel Lobo chegou ao Prata, onde fundou a fortaleza do Santíssimo Sacramento em frente às ilhas de São Gabriel. Contudo, a expedição não pôde resistir ao ataque combinado das forças coloniais espanholas e dos exércitos indígenas das missôes jesuíticas, grupos para os quais a presença portuguesa no Prata constituía uma grande ameaça. A destruição de Sacramento, levada a cabo oito meses após sua fundação, irritou profundamente o Príncipe Regente que, sob ameaça de guerra, forçou a Coroa espanhola a restituir-lhe a posse do território conquistado no Tratado Provisional de 1681. A fraqueza da Espanha obrigada a ceder por meio da diplomacia o que seus vassalos na América haviam conquistado pelas armas voltaria a se repetir em 1715 e ainda em 1763, refletindo a contradição que podia haver entre os interesses dos colonos e os da metrópole.

Foram bastante difíceis os primeiros anos que se seguiram ao restabelecimento dos portugueses na Colônia, em 1682, quando as restriçōes do governo de Buenos Aires, que procurava impedir o contrabando e a exploração do gado selvagem que abundava na campanha, se somaram à corrupção generalizada que marcou o governo de Cristóvão Ornelas de Abreu (1683-1689). A situação melhorou consideravelmente sob as administrações de Francisco Naper de Lencastre (1689-1699) e de seu sucessor, Sebastião da Veiga Cabral (1699-1705), com o incremento da política de povoamento e uma intensa exploração das riquezas pecuárias da Banda Oriental. ${ }^{3}$

A Guerra da Sucessão Espanhola colocaria Portugal e Espanha em campos opostos na Europa, resultando na irrupção das hostilidades no Prata e no abandono da Colônia aos castelhanos em 1705. A guerra terminou com a assinatura dos tratados de Utrecht, nos quais Felipe V teve de fazer várias concessões a fim de obter o reconhecimento das nações europeias à ascensão dos Bourbon ao trono espanhol. O tratado de paz com Portugal, assinado em 1715, assegurou aos portugueses a devolução do território da Colônia do Sacramento.

A partir de então, a Coroa portuguesa iniciou uma verdadeira política de povoamento na região, enviando sessenta casais da província de Trás-os-Montes, em 1718, para dar início à agricultura e desenvolver a criação de gado, assim como garantir uma guarnição militar permanente. As constantes deserções dos soldados que serviam em Sacramento levaram o Conselho Ultramarino a defender o envio de 
casais, argumentando que "à experiência de tantos desertores será melhor que vão casais porque não é tão fácil largarem suas mulheres e filhos e irem viver em reino estranho". ${ }^{4} \mathrm{Da}$ mesma forma que o uso do sistema de degredo, a política de implementar a colonização através dos casais estava intimamente ligada à instituição militar. Cedo os povoadores foram enquadrados no sistema militar, pois antes mesmo que chegassem ao seu local de destino, a Coroa já enviara trezentas armas para a formação de "algumas companhias de ordenança dos mesmos casais que ajudem a defesa da dita praça".

A notícia da entrega da "Colônia do Sacramento e seu território", segundo os termos do Tratado de Utrecht, não foi bem recebida em Buenos Aires. O cabildo escreveu ao rei que a devolução da Colônia aos lusos resultaria num gravíssimo prejuízo à Coroa espanhola e aos habitantes das províncias de Buenos Aires, Paraguai e Tucumã, assim como aos índios das missões jesuíticas. Dizia que todos necessitavam da caça do gado selvagem que vivia na Banda Oriental, uma vez que a contínua exploração e a seca haviam extinguido o gado na campanha bonaerense. ${ }^{6}$ Para o governador de Buenos Aires, o território da Colônia, não delimitado pelo Tratado de Utrecht, era somente o coberto pela artilharia da praça. Segundo ele, se antes os portugueses tinham o usufruto da campanha, o mesmo não passava de roubo, o que seria evitado com o povoamento da margem norte do Rio da Prata pelos espanhóis.

$\mathrm{Na}$ tomada de posse, o governador Manuel Gomes Barbosa expôs o que os portugueses entendiam como sendo o território da Colônia: "tanto para a parte do norte, por onde se continua atualmente o domínio de Portugal, como para a parte do leste, e foz do Rio da Prata" ${ }^{8}$ Por isso pediu aos comissários espanhóis a retirada da guarda do rio San Juan, situada a cinco léguas de Sacramento. Recebeu uma negativa com base no argumento de que o território da Colônia do Sacramento se restringia ao alcance de um tiro de canhão disparado da fortaleza, ideia do governador de Buenos Aires aprovada pela Coroa espanhola. Seguindo as ordens de Lisboa, Gomes Barbosa fez registrar seu protesto contra a limitação imposta pelos espanhóis e deu início às obras de reconstrução da fortaleza.

Se os primeiros tempos ainda foram difíceis, devido aos problemas de abastecimento que marcaram o governo de Manuel Gomes Barbosa (1716-1722), a situação mudaria radicalmente com a chegada do seu sucessor. A junção do apoio decidido da Coroa à grande capacidade administrativa do governador Antônio Pedro de Vasconcelos (1722-1749) foram os fatores responsáveis por um período de grande desenvolvimento que pode ser considerado como o apogeu da presença portuguesa no Rio da Prata.

Porém, a prosperidade dos habitantes da Colônia do Sacramento preocupava a Coroa espanhola, lesada pelo intenso contrabando, enquanto os colonos e os índios das missóes conviviam a contragosto com a concorrência portuguesa na exploração do gado selvagem. A tensão permanente, alimentada pelos frequentes conflitos com os espanhóis e indígenas na campanha, chegaria ao auge em outubro de 1735, quando as tropas castelhanas apareceram em frente aos muros da Colônia do Sacramento, iniciando um sítio que duraria dois longos anos até que a paz voltasse às margens do Rio da Prata, em setembro de 1737.

O início das hostilidades no Prata foi a consequência de uma série de tensões que, na Europa e na América, opunham os interesses dos espanhóis aos dos portugueses; o pretexto para iniciá-las foi um pequeno incidente diplomático ocorrido em Madri. Em um domingo de carnaval, 20 de fevereiro de 1735, os criados do embaixador português na corte espanhola, Pedro Álvares Cabral, Senhor de Belmonte, libertaram um homem que estava sendo conduzido preso, por soldados, pelas ruas de Madri, dando-lhe acolhida na casa do embaixador. Dois dias após, cem soldados invadiram o palácio do Senhor de Belmonte, prendendo todas as pessoas que lá encontraram. Embora Pedro Álvares Cabral protestasse contra a violência, de nada adiantou sua intervenção.

A chegada da notícia desse incidente a Lisboa provocou a divisão dos conselheiros de D. João V entre os que propunham uma conciliação e os que exigiam uma represália imediata. O segundo grupo venceu e, a 13 de março, sessenta soldados e três oficiais ocuparam todas as entradas da casa do embaixador espanhol, Marquês de Capecelatro, prendendo doze criados seus que foram levados à cadeia do Limoeiro. ${ }^{9}$ 
O incidente diplomático que quase originou um conflito bélico entre as Coroas ibéricas na Europa e foi responsável pela irrupção da guerra no Prata, foi na verdade o estopim da tensão no relacionamento luso-espanhol que vinha estremecendo desde 1733. O casamento dos príncipes herdeiros de Portugal e Espanha com as infantas espanhola e portuguesa, combinado em 1725 e realizado quatro anos após na fronteira luso-espanhola, fora pactuado num momento de irritação contra a corte francesa, que desfizera os ajustes para o casamento do delfim da França com a infanta de Espanha e não correspondia a um desejo sincero de maior aproximação com Portugal, de quem Filipe V guardava ressentimentos desde a Guerra da Sucessão Espanhola. Por outro lado, o príncipe das Astúrias era alvo constante das intrigas de Isabel Farnésio, a segunda esposa de Filipe V. Enquanto Isabel era a principal interessada em impedir que Felipe V cumprisse sua intenção de abdicar, D. João V manifestava a esperança de que a ascensão de seu genro ao trono espanhol aumentaria sua influência na corte de Madri. Jaime Cortesão sustenta a hipótese de que a intimidade que o embaixador português mantinha com os príncipes e seu envolvimento entre os partidários da abdicação de Felipe $\mathrm{V}$ foram os fatores responsáveis pela antipatia que Isabel Farnésio e seu valido, o primeiro ministro D. José Patiño, lhe devotavam. ${ }^{10}$

Além das intrigas da corte, a situação internacional também contribuiu para o fim da harmonia que existiu, entre 1725 e 1733, entre as duas Coroas ibéricas. Em 1733, D. José Patiño negociou uma aliança franco-espanhola que ia contra os interesses portugueses, pois, por meio desse pacto, a França comprometia-se a ajudar a Espanha a conquistar os reinos de Nápoles e Sicília (que então pertenciam à Áustria, aliada de Portugal) para o príncipe Carlos, filho de Felipe V e Isabel Farnésio. ${ }^{11}$

A reviravolta da política de alianças elaborada pela diplomacia espanhola agradou sobremaneira aos tradicionais inimigos dos habitantes da Colônia, os jesuítas e o cabildo de Buenos Aires que, em 15 de abril de 1733, escreveu ao rei queixando-se dos "excesos cometidos en los ganados vacunos de la otra banda por los portugueses de la Colonia". ${ }^{2}$ Patiño aproveitou o momento e, com a dupla finalidade de agradar os portenhos e hostilizar os portugueses, inteirou o novo governador do Rio da Prata, D. Miguel de Salcedo, das queixas do cabildo de Buenos Aires, ordenando-lhe que durante seu governo se informasse dos novos caminhos abertos pelos portugueses para o Brasil e destruísse todos os estabelecimentos, quintas, estâncias e animais que os portugueses possuíssem fora da área coberta pela artilharia dos muros de Sacramento, solicitando a ajuda dos índios missioneiros se fosse necessário. Devia ainda impedir todo o comércio entre portugueses e espanhóis e limitar a navegação dos lusitanos, no Rio da Prata, às rotas estritamente necessárias para a ligação da Colônia aos demais domínios portugueses. ${ }^{13}$

Assim que chegou a Buenos Aires, em março de 1734, Salcedo empenhou-se em cumprir as ordens recebidas. Na repressão ao contrabando, ordenou a substituição dos antigos fiscais reais, sendo que alguns deles foram presos e tiveram seus bens confiscados. ${ }^{14}$ Ainda em março do mesmo ano, Salcedo escreveu ao governador Antônio Pedro de Vasconcelos informando-lhe da "expresa orden del Rey mi amo para arreglar, y demarcar los limites de esa Colonia". Vasconcelos respondeu-lhe que "se achava sem as instruções ou poderes de S. Majestade, para entrar nesta conferência". Salcedo insistiu no assunto em outras duas cartas, enquanto Vasconcelos continuava a alegar a sua falta de competência para determinar os limites do território da Colônia do Sacramento. ${ }^{15}$ Entretanto, em 18 de abril de 1735, D. José Patiño comunicou ao governador Salcedo que o rei resolvera "que sin esperar a que formalmente se declare la guerra con los Portugueses, y solo en virtud de esta orden, se sorprenda, tome y ataque la ciudady Colonia del Sacramento". ${ }^{16}$

Entre os preparativos para o ataque a Sacramento, o governador Salcedo ordenara a saída dos portugueses e ingleses de Buenos Aires. Mais de trinta ingleses conseguiram burlar a vigilância dos espanhóis e passaram para a Colônia, onde foram bem recebidos pelo governador Vasconcelos, que os juntou à tripulação do bergantim real, que teve como missão dar caça aos transportes e comunicações que os espanhóis faziam entre as duas margens do Rio da Prata. ${ }^{17}$

Enquanto isso, na Europa, os governos de Lisboa e Madri iniciavam os preparativos para a guerra. Em cumprimento aos tratados de aliança com Portugal, em junho, entrou no Tejo uma esquadra inglesa 
composta de trinta navios e mais de doze mil homens. Ao mesmo tempo, a Coroa ordenou ao governador Antônio Pedro de Vasconcelos que se prevenisse contra qualquer ataque espanhol, aviso desnecessário, já que o mesmo sabia do que se passava em Buenos Aires através das informações fornecidas pelos espanhóis que visitavam a Colônia e pelos espiōes que mantinha naquela cidade. ${ }^{18}$

$\mathrm{Na}$ campanha, o bloqueio hispano-indígena foi estreitando aos poucos os movimentos dos portugueses e, em 30 de maio de 1735, o comerciante José Meira da Rocha escrevia que "está isto tão miserável que nem sequer lenha nos deixam os castelhanos tirar da campanha, tomando para seu poder todos os carros e escravos que a vão buscar, e mandando dizer ao depois aqui vergonhosíssimas graças e chascos". ${ }^{19}$ Em 29 de julho iniciou-se o bloqueio naval, quando um navio que saía carregado da Colônia com destino à Bahia foi apresado pelos espanhóis. ${ }^{20}$

A tensão cotidiana degenerou em pânico em outubro, quando um destacamento espanhol avançou sobre os arredores de Colônia, destruindo as quintas dos povoadores e pondo em retirada a cavalaria portuguesa. As tensões manifestaram-se então contra as autoridades portuguesas, pois começou a circular a notícia de que embora o governador soubesse da possibilidade de um ataque espanhol, não providenciara a evacuação dos colonos, que viram suas lavouras destruídas e o gado apresado pelo inimigo, tendo de se retirar para a fortaleza às pressas sem poderem salvar os alimentos que seriam necessários durante o longo cerco. ${ }^{21}$

De fato, embora o governador Vasconcelos tivesse sido avisado dos preparativos de guerra de D. Miguel de Salcedo, os espiōes que mantinha em Buenos Aires asseguraram-lhe que o mesmo tinha falta de gente e via-se desprevenido para um ataque. Para o governador da Colônia, os preparativos dos espanhóis tinham a finalidade de fazer os portugueses abandonarem as estâncias, pois ele não acreditava no rompimento das hostilidades sem uma formal declaração de guerra na Europa. ${ }^{22}$

Embora não houvesse ordenado a evacuação da campanha, o que seria ceder às pressões espanholas de não sair do espaço coberto pela artilharia, assim que recebeu o aviso de Lisboa, o governador Vasconcelos deu ordem para que se reforçasse a muralha, ainda inconclusa. Os trabalhos de fortificação continuaram sem parar nos domingos ou dias santos, com a participação de toda a população, inclusive dos meninos da escola, que executavam o serviço cantando como uma forma de suavizar o trabalho. Ao mesmo tempo, o governador enviou ao arrabalde de Veras 120 cavaleiros destinados a impedir o avanço dos castelhanos, ${ }^{23}$ medida que se revelou insuficiente, pois um destacamento de 500 soldados espanhóis pôs em retirada a cavalaria portuguesa, dando início à destruição das quintas dos arrabaldes. ${ }^{24}$

Em 22 de outubro de 1735, o governador Vasconcelos ordenou uma mostra para verificar quantos dos moradores eram destros no tiro. $\mathrm{O}$ mesmo queixou-se de que dentre os muitos moradores, só aprovou cento e vinte, os quais repartiu em quatro companhias destinadas à defesa da área litorânea, designando um oficial para que os exercitasse no manejo das armas. ${ }^{25} \mathrm{O}$ ataque dos espanhóis mobilizou todos os segmentos da população da Colônia para acudir à defesa da praça.

Os civis foram agrupados em companhias que preservavam a divisão dos grupos sociais e dos elementos que se destacavam nesses grupos. O escrivão da Fazenda Real, Caetano do Couto Veloso, formou um destacamento com os seus dez escravos enquanto os comerciantes formaram uma companhia sob as ordens do seu companheiro de ofício, José Meira da Rocha.

De 28 de novembro até 9 de dezembro de 1735, os espanhóis bombardearam a Colônia do Sacramento causando "horroroso estrago nas propriedades da povoação", segundo o alferes Silvestre Ferreira da Silva, um dos cronistas do cerco. ${ }^{26} \mathrm{O}$ bombardeio abriu uma brecha de duzentos palmos na muralha, e mesmo que ela fosse constantemente reparada pelos defensores durante a noite, o governador de Buenos Aires exigiu a rendição da praça. ${ }^{27}$ Diante da negativa do governador da Colônia, as tropas espanholas começaram a organizar-se para o assalto. Porém uma bala da artilharia portuguesa atingiu o centro da formação inimiga, causando uma grande confusão que desbaratou o assalto à praça sitiada. ${ }^{28}$

Em 6 de janeiro de 1736 chegaram os reforços que se concentravam no Rio de Janeiro, somando homens recrutados naquela capitania, em Minas Gerais e na Bahia. ${ }^{29}$ A expedição de socorro garantiu 
a supremacia naval aos portugueses, ocasionando a retirada do governador de Buenos Aires, que levou consigo a infantaria e a cavalaria, deixando quinhentos cavaleiros no campo de bloqueio a fim de impedir a saída dos portugueses do recinto fortificado. A morte do jesuíta que comandava os índios missioneiros aumentou a deserção entre eles, que por fim também foram mandados para casa. ${ }^{30}$

Porém, se a chegada da expedição de socorro diminuiu a pressão dos espanhóis sobre a Colônia do Sacramento, surgiram diversos atritos entre os moradores e os recém-chegados. O recrutamento forçado trazia diversos problemas; o principal era a dificuldade em manter a disciplina entre homens sem treinamento militar. Mal desembarcado o destacamento da Bahia, "começaram os soldados com distúrbios e desgostos a inquietar a praça. Mostravam que da guerra não tinham experiência, menos sofrimento para os trabalhos de um sítio rigoroso. Sabiam melhor contender com os domésticos que disputar com os estranhos", segundo Simão Pereira de Sá. ${ }^{31}$ Parece mesmo que os baianos trouxeram mais problemas que auxílio e, por fim, o governador Vasconcelos resolveu desembaraçar-se deles mandando-os embarcar para Laguna a fim de buscar carne para o sustento da praça, de onde o destacamento saía "mal quisto com o povo por alguns insultos cometidos aos paisanos". ${ }^{32}$

As tropas desembarcadas deveriam substituir os civis que defendiam a praça. Mas nem sempre a substituição deu-se sem problemas. Devido à sua elevada posição social na Colônia, o comerciante José Meira da Rocha recebeu o comando de uma companhia que incluía comerciantes e soldados. Meira da Rocha não deixou de registrar que durante os cinco meses em que comandou este grupamento teve de ter grande paciência para aturar a falta de disciplina dos seus subordinados, que pediam para almoçar e voltavam à tardinha ou pediam para jantar e só voltavam no dia seguinte. Caso se negasse a dar permissão para as suas saídas, iam queixar-se ao governador,

que me não podiam aturar com impertinências e medos demasiados, que sempre queria ter ali a gente amarrada, e a trabalhar nos parapeitos, e que o melhor seria entregar a bateria a outrem e juntamente que ora queria estar sempre atirar ao inimigo, ora não queria, trocando as melhores ocasiōes para as piores e, para dizer tudo, fizeram-me meio doido. ${ }^{33}$

O governador, por sua vez, tentava apaziguar os ânimos, recusando-se a castigar a falta de disciplina dos soldados e ordenanças, dizendo-lhe que "não estávamos em ocasião disso, e que sofresse eu 21 homens que também ele sofria toda a praça". ${ }^{34}$ As tensões entre os dois grupos manifestavam-se através do pouco caso com que os soldados tratavam a autoridade de Meira da Rocha, ausentando-se por longas horas dos seus postos e também através de queixas ao governador.

José Meira da Rocha estava consciente de que os atritos que tinha com seus subordinados eram consequência do seu empenho em cumprir bem sua missão, pois comentou que, no tempo em que comandava a bateria, mantinha todo o equipamento limpo e em ordem, com os canhões sempre carregados e apontados para o inimigo. A situação mudou completamente depois que o capitão Antônio Carvalho e sua companhia ocuparam o posto que anteriormente comandava, o qual descreve então como "mui diverso, por estar a artilharia uma descarregada, e outra desapontada, e tudo sujo e miserável, que certamente paga Sua Majestade soldo a homens que eles lhes deviam pagar a água que bebem no seu reino". ${ }^{35}$

Segundo Meira da Rocha, assim que o governador viu o estado em que se encontrava a bateria, deixada a cargo dos reforços vindos do Rio de Janeiro, ordenou ao próprio e aos demais comerciantes que, assim que ouvissem o sino anunciar um ataque inimigo, acorressem à mesma bateria para cuidar da artilharia. Porém, para Meira da Rocha tal cuidado não seria de grande utilidade, já que "na bateria ninguém hoje poderá parar em caso de assalto por estarem as pessoas nela a peito descoberto, por que como os parapeitos eram de surrões de couro cru cheios de terra, e neles não houve cuidado, apodreceu o couro, e a terra caiu ao mar". ${ }^{36}$

Porém, a atuação mais importante dos comerciantes não era a sua participação ativa na defesa da praça, mas sim, a de fornecer empréstimos que possibilitassem ao governador Vasconcelos realizar o pagamento das tropas. Segundo Simão Pereira de Sá: "A guarnição aflita e cansada, sobre a queixa de 
mal paga, violentamente obedecia, e servia com repugnância”. Esta situação foi remediada pelo oferecimento, ao governador, por "Domingos Alvarez Calheiros, José da Meira, e outros mercadores, cabedal bastante com que se fez pagamento geral às tropas, contentando assim a aqueles que pelas queixas se podiam fazer rebeldes aos superiores, traidores à pátria”. ${ }^{37}$

Em situação de perigo intenso como a guerra, os escravos eram armados e serviam sob o comando dos seus senhores, como foi o caso dos cativos do escrivão da Fazenda Real em Colônia, Caetano do Couto Veloso que, com seu filho e dez escravos de sua propriedade, apresentaram-se ao governador para ajudar a reconstruir a muralha, que as chuvas haviam arruinado. Couto Veloso recebeu a incumbência de defender um setor dos muros com "dez negros armados de espingardas, e chuços". Mais tarde, foi transferido para o porto, onde continuou o serviço com "os seus dez escravos que a todas as funções o acompanhavam fazendo rondas e sentinelas por toda aquela parte". Os escravos continuavam a ter os piores serviços, mesmo em tempo de guerra, pois o governador mandou que o escrivão juntasse seus homens à forças do capitão Pedro Lobo "compostas de sessenta homens pretos" para que, numa perigosa expedição, saíssem do recinto fortificado para demolir o que restava das construções extramuros, a fim de fornecer madeiras para a confecção de plataformas para a artilharia. ${ }^{38}$

Silvestre Ferreira da Silva relacionou os negros que ajudaram a guarnecer a praça, sem identificar se eram escravos, ou não. Nos baluartes de Santo Antônio e no de São João estavam a postos "alguns pretos de préstimo para o manejo da lança e da artilharia do dito baluarte". Na bateria de Santa Rita, quatro negros cuidavam da artilharia e na bateria de São Pedro de Alcântara, estão relacionados mais sete negros. Curiosamente, Ferreira da Silva omitiu a presença dos escravos na defesa da zona portuária, a qual foi encarregado de defender, referindo-se somente a "cem homens avulsos", ${ }^{39}$ enquanto Simão Pereira de Sá escrevia que "a mais parte da mencionada Marinha, guarnecia uma numerosa companhia de escravos a cargo de Silvestre Ferreira da Silva”. ${ }^{40}$ Nessa companhia encontravam-se os cativos do escrivão da Colônia, pois Sá acrescentava que nela serviam de oficiais, Caetano do Couto Veloso, Pedro Lobo Botelho e Clemente da Silva Pais.

Os espanhóis procuraram tirar vantagem da presença dos escravos entre os defensores de Colônia, oferecendo-lhes a liberdade, caso desertassem e passassem para os domínios do Rei Católico. O governador Antônio Pedro Vasconcelos também buscou favorecer a deserção entre as fileiras inimigas, porém não prometia nada aos escravos, dizendo que "não disputa aos escravos a fuga do domínio de seus senhores, por ser contra a moral cristã". ${ }^{41}$ Provavelmente os portugueses não deixaram de se utilizar da contrapropaganda, como fizeram durante o cerco de 1705, quando o governador Sebastião da Veiga Cabral mandou espalhar o boato de que o governador de Buenos Aires queria reduzir toda a população sitiada à condição de prisioneiros e se apoderar dos seus escravos, escravizando também os negros e mulatos livres. ${ }^{42}$

O pequeno espaço físico ocupado pelas fortificações, que tornava difícil o cotidiano dos moradores, piorou com a chegada dos reforços, pois os mantimentos não eram suficientes para todos. $\mathrm{O}$ início do inverno também causou o aumento de doenças, especialmente dos soldados que vinham de regiōes com clima tropical. ${ }^{43}$

São inúmeros os relatos de doenças entre os sitiados, geralmente causadas pela fome, ingestão de alimentos estragados, disseminação do escorbuto, por falta de alimentos frescos, e mesmo pelo clima frio do inverno, ao qual muitos soldados que vinham da costa brasileira não estavam acostumados. $\mathrm{O}$ alferes Silvestre Ferreira da Silva registrou que: "Assim o experimentou naqueles meses de inverno toda a povoação da Colônia, em que a fome (como fera que tudo atropela) nos obrigou a comer cavalos, cães, gatos e outros imundos animais, que procurava a necessidade" ${ }^{44}$

Simão Pereira de Sá descreveu na sua característica linguagem barroca a terrível situação da praça sitiada:

Era tão lamentável, e geral a falta de mantimentos na praça que a nenhuma espécie de animal imundo perdoava a fome, escogitando [sic] a necessidade admiráveis viandas das ervas agrestes, que incultamente, pro- 
duzia a terra; valia uma galinha quatro mil réis, e como ainda na extremidade era barata a exorbitância, apareciam poucas para os enfermos da mesma fome. Convalesciam os doentes de queixas graves com carne salgada, e corrupta. Eram os ratos preciosa venatória para os mais mimosos na criação. Custava o gato a meio peso castelhano. O quarto de cão a oitenta réis. De algumas estrebarias violentamente tiravam as bestas e sem igualdade nos quinhões, cada um levava o seu pedaço à força de armas, ficando mais lucrado o que era mais valente. ${ }^{45}$

Entretanto, novos reforços se faziam necessários, pois a notícia de que a Coroa espanhola preparava duas naus para aumentar as suas forças no Prata fizera D. João V ordenar a ida de uma frota em socorro a Colônia. ${ }^{46}$ A 25 de março de 1736, zarpavam de Lisboa duas naus de 60 peças e uma fragata de 54, sob o comando do coronel Luís de Abreu Prego que, com o pretexto de acompanhar a frota mercante do Rio de Janeiro, destinavam-se a reforçar a presença naval de Portugal no Rio da Prata. Seguia com o coronel Prego o mestre de campo André Ribeiro Coutinho, considerado um dos mais brilhantes oficiais portugueses, com larga experiência no Estado da Índia. Posteriormente, acrescentar-se-iam mais duas fragatas, que deveriam acompanhar a frota da Bahia, a qual zarpou em 21 de agosto. Os navios de guerra seguiam com uma tripulação maior do que a necessária, à qual se acrescentaria um destacamento a ser retirado da guarnição do Rio de Janeiro. Com relação à atuação que se esperava da frota, D. João $\mathrm{V}$ dava preferência à tomada de Montevidéu, mas também ordenava a fortificação da margem sul da barra do Rio Grande de São Pedro. ${ }^{47}$

$\mathrm{Na}$ altura das ilhas Canárias, os navios de guerra comandados por Prego se adiantaram aos navios mercantes da frota e seguiram para o Rio de Janeiro, para onde a Coroa já havia mandado um navio com ordem para que o governador Gomes Freire de Andrade seguisse para o Rio de Janeiro, onde deveria assumir o governo da capitania. ${ }^{48} \mathrm{O}$ brigadeiro José da Silva Pais, governador interino do Rio, desde 12 de março de 1735, fora encarregado de armar alguns navios leves para se juntarem aos reforços que em breve chegariam de Lisboa, devendo incorporar-se à expedição de socorro para comandar as operações terrestres contra os espanhóis. ${ }^{49}$

A situação em Sacramento era tão crítica que quando chegaram remessas de alimentos nos navios de socorro, não se sabia como cozinhá-las, pois não havia madeira disponível, e por isso "já não há casa que tenha porta interior, nem coisa de madeira que se não tenha queimado e muitos comprando carros para o mesmo efeito". ${ }^{50}$ Além do problema ocasionado pela falta de lenha, havia a circunstância de que a maior parte dos mantimentos recebidos era composta de farinha de mandioca e carne salgada, alimentos impróprios para serem consumidos pelos doentes, que ao invés de melhorarem, morriam por causa da dieta que lhes era imposta pelas circunstâncias. ${ }^{51}$

O pedido do brigadeiro José da Silva Pais ao governador do Rio de Janeiro, Gomes Freire de Andrada, de que se colocasse fim aos abusos nos gastos com os remédios, que já passavam de três mil cruzados, parece sugerir que houve super faturamento no valor dos mesmos. ${ }^{52}$ Porém, os crescentes gastos com a saúde também se relacionam ao aumento do número de doentes. Silva Pais liberou os reforços do Rio de Janeiro do desconto a que eram submetidos para a assistência do hospital, pois embora esta fosse disposição do regimento do Rio, a guarnição de Sacramento não era obrigada a contribuir com as despesas do hospital, através do desconto do seu soldo. Contudo, os militares cariocas não deixaram de reclamar que no hospital de Sacramento "morrem muitos soldados à míngua, por não terem um caldo de galinha e são tratados como se pode, e [portanto] não devem dar o vintém e eles o que lhe toca". ${ }^{53}$

Enquanto Rio de Janeiro, Bahia e Minas Gerais enviavam seus reforços por via marítima, a capitania de São Paulo foi encarregada de atacar as missões jesuíticas para forçar a retirada das tropas indígenas do cerco à Colônia. Em 17 de agosto de 1736, em nome de Sua Majestade, o secretário Antônio Guedes Pereira escrevia ao Conde de Sarzedas, governador de São Paulo, para que convidasse os sertanistas da cidade a invadirem os domínios castelhanos, serviço que seria pago com mercês, honrarias e a promessa de que "dos índios que tomarem se poderão servir, com esta distinção, que se forem gentios ficarão seus escravos, e se forem cristãos, ficarão prisioneiros de guerra, mas com a obrigação de os servirem". ${ }^{44}$ 
Embora entre os sitiados existisse a esperança de que dois mil paulistas viessem por terra para forçar os espanhóis a levantarem o cerco, ${ }^{55} \mathrm{o}$ certo é que tudo não passava de boato ditado pelo desespero ou mesmo conscientemente criado para elevar o moral da população. Os reforços de São Paulo, na verdade, não passavam de 180 homens chefiados por Cristóvão Pereira de Abreu, sertanista que tinha grandes interesses na exploração do gado sulino.

Essa expedição não passou do Rio Grande de São Pedro, pois Pereira de Abreu tinha poucos homens, mal armados, e temia que a guarnição de Montevidéu lhe impedisse o acesso à Colônia. O sertanista criticou a estratégia portuguesa de concentrar os esforços numa ofensiva marítima, dizendo que "se admira muito de que todas as forças se oponham no mar e nenhuma por terra por onde com muito pouco já se teria concluído tudo". ${ }^{56}$ Mesmo que os paulistas não tivessem entrado em luta direta com os espanhóis, contribuíram para a manutenção de Sacramento, através do envio de carne e peixe e do apoio que deram à fortificação do Rio Grande de São Pedro, iniciado em fevereiro de 1737, por ordem do brigadeiro José da Silva Pais, como alternativa às fracassadas tentativas de tomar Montevidéu e fortificar Maldonado.

Com o objetivo de aliviar a falta de alimentos na Colônia do Sacramento, ordenou-se a evacuação da população civil. No navio que comandava o bloqueio a Montevidéu, Silva Pais escreveu a Gomes Freire, em 24 de setembro de 1736, dizendo-lhe que: "escrevo à Colônia hoje mande logo para baixo parte das embarcaçóes que foram com mantimentos e lhe recomendo muito mande nelas o maior número de bocas inúteis pode ter naquela praça, para assim poderem chegar a mais algum tempo os mantimentos". ${ }^{57}$

Alguns dos casais que se retiraram de Sacramento foram enviados ao Rio de Janeiro, onde encaminharam pedido de ajuda para o pagamento da passagem e da alimentação, alegando não terem "coisa alguma de seu, que todo o seu cabedal, se algum tinham, ficou na dita praça onde gastaram enquanto acharam o que comprar para alimentos". ${ }^{5}$ Para receber ajuda de custo da Fazenda Real os casais tinham de provar serem pobres; terem feito parte do grupo que, em 1718, começou o povoamento da Colônia, a pedido do rei; e terem-se retirado dela sob ordem do governador Vasconcelos. Dos casais que fizeram o pedido, em dezembro de 1736, só receberam a ajuda de custo de meio tostão por dia, cada um, enquanto durasse o sítio da Colônia, Inácio Gonçalves, José de Almeida e Joana Maria, por apresentarem todos os requisitos necessários. ${ }^{59}$

Enquanto alguns casais seguiram para o Rio de Janeiro, outros foram mandados para o Rio Grande, a fim de dar início ao povoamento da região a partir de 1737, ano em que também os comerciantes abandonaram a praça, como vemos na carta em que, do Rio de Janeiro, Meira da Rocha escreveu ao comerciante lisboeta Francisco Pinheiro:

Meu senhor, depois de me haver na Nova Colônia desenganado claramente de que os portugueses naquela paragem já não haviam de aliviar a praça nem fazer mais do que aturar as afrontas castelhanas, resolvi-me e mais os outros comissários dela a largarmo-la em poder dos militares que somente nela se acham, por que também as famílias paisanas de crianças e mulherio a desampararam, embarcando-se uns para este Brasil, e outros para o porto de São Pedro ou Rio Grande onde de presente se acham os socorros que desta haviam ido como também da Bahia e Pernambuco para a mesma Colônia, em cuja praça não pararam por terem os castelhanos à vista. ${ }^{60}$

Os que não seguiram diretamente para o Rio Grande de São Pedro foram para lá enviados sem muita demora. Em 1738, Gomes Freire remeteu para Rio Grande muitos casais que anteriormente haviam sido evacuados da Colônia do Sacramento com destino ao Rio de Janeiro e Laguna. ${ }^{61}$

A paz voltou ao Prata em primeiro de setembro de 1737, quando chegou a Sacramento a nau de guerra "Boa Viagem" com a notícia da assinatura do armistício, em 16 de março do mesmo ano, em Paris, pelos representantes das Coroas portuguesa e espanhola, ordenando a cessação das hostilidades e a manutenção do status quo. Com o armistício de 1737, inicia-se uma nova fase da história da Colônia do Sacra- 
mento. Como bem observou Rego Monteiro, "terminou o período áureo da Colônia do Sacramento, jamais voltaram a ter seus arredores aquela riqueza de produção, que fazia dela a cobiça espanhola" ${ }^{62}$ De fato, de 1737 a 1777, o cotidiano dos habitantes de Sacramento foi marcado pelo bloqueio constante a que os espanhóis submeteram o povoado, o que levou o historiador uruguaio Aníbal M. Riverós Tula a compará-lo à também estratégica posição de Gibraltar, ${ }^{63}$ possessão inglesa na costa sul da Espanha.

A comparação da situação da Colônia do Sacramento com a de Gibraltar não escapou aos contemporâneos. Martinho de Mendonça de Pina e de Proença, que governou interinamente a capitania de Minas Gerais, durante o cerco à Colônia de Sacramento, previa grandes problemas em manter duas fortalezas tão distantes entre si como Colônia e Rio Grande, sendo "necessário sustentar presídios, como Inglaterra a Gibraltar". ${ }^{64} \mathrm{Na}$ correspondência trocada com o general Gomes Freire de Andrada, Martinho de Mendonça de Pina e de Proença mostrava sua preocupação com a manutenção de uma praça mantida sob bloqueio contínuo, que também comparou a Mazagão, praça-forte portuguesa situada na costa atlântica do Marrocos. ${ }^{65}$

Efetivamente, a partir de então, a situação da Colônia tornou-se parecida com a das possessões portuguesas na costa marroquina, onde, segundo Boxer, "as guarnições das praças só controlavam o terreno à volta das muralhas, até onde alcançava o canhão. Nesse terreno, cultivavam os cereais, vegetais, frutas e pastoreavam os cavalos e o gado". ${ }^{66} \mathrm{O}$ padre jesuíta Florián Paucke, que visitou a Colônia do Sacramento em 1749, observou que o gado era recolhido à praça durante a noite, para evitar que fosse apresado pelos espanhóis, ${ }^{67}$ o que também acontecia em Mazagão, onde um dos portões chamava-se "porta dos bois", justamente por ser utilizado para conduzir o gado para as pastagens do campo vizinho. ${ }^{68}$ Francisco Millau, na sua Descripción del Río de la Plata, de 1772, descreve a existência de uma forte paliçada construída pelos espanhóis que, de uma praia a outra, confinava os portugueses na península ocupada pela Colônia do Sacramento. No cordão de isolamento ficava sempre de prontidão um destacamento de tropa que fazia parte da guarnição de Buenos Aires. ${ }^{69}$

Porém, tanto Paucke como Millau acentuam que o caráter militar da Colônia do Sacramento não excluía a intensa atividade comercial que ali se realizava. Mais uma vez, podemos traçar um paralelo com Mazagão que, durante o período filipino, foi um centro de comércio muito visitado pelos mercadores europeus, "atraídos pela segurança do porto, pela inexistência de barreiras alfandegárias na entrada das mercadorias e pela facilidade dada pelas autoridades no trato com os comerciantes mouros e judeus" ${ }^{70}$

De fato, se os espanhóis conseguiram conter a expansão portuguesa no atual território uruguaio, não conseguiram acabar com o contrabando em definitivo. Paucke assim descreveu o bloqueio que os espanhóis impunham ao povoado:

Parece-me que os Portugueses vivem tão apertados e são tão sitiados pelos espanhóis, como o são, atualmente, os judeus, em nossos países. Eu mesmo vi os sentinelas ao redor da cidade; a mim me pareceu que ela estivesse bloqueada ininterruptamente. É possível que, a partir do lado da terra, se possa fazer penetrar algo, se - bem entendido - os sentinelas não forem ladrões ou intermediários. Eu não sei se ocorre tal coisa, mas é provável que sim. ${ }^{71}$

De fato, o campo de bloqueio espanhol, ao invés de impedir, contribuiu para o desenvolvimento do contrabando entre os súditos de Portugal e Espanha. A limitação do uso da campanha ao pequeno espaço permitido pelo campo de bloqueio impediu a retomada da produção agrícola e pecuária por parte dos habitantes da Colônia do Sacramento, que tiveram que buscar o abastecimento entre os espanhóis. A procura por gêneros alimentícios em Buenos Aires justificava a presença constante de embarcações portuguesas na cidade que, na maioria das vezes, transportavam mercadorias de contrabando. Também era frequente a passagem de suprimentos e contrabando, através da guarnição responsável pela manutenção do campo de bloqueio. Segundo Fabrício Prado: "Tal momento marca uma inflexão da estratégia lusitana. A Colônia do Sacramento, a partir de então, assumia a constituição de um porto comercial sem um entorno agrícola e uma possível moeda de troca por territórios de Espanha” ${ }^{72}$ 
A história da Colônia do Sacramento apresenta diversas facetas que foram diferentemente realçadas pelos historiadores, de acordo com as suas próprias interpretações. Centro de contrabandistas, mas também posto avançado da fronteira, Sacramento é um tema fascinante pela sua história sui generis, no interior do quadro do sistema colonial da América portuguesa, onde a riqueza estava na agricultura, ou nas minas, e as invasōes estrangeiras constituíram-se em episódios isolados e inconstantes, ao contrário do que se dava na Colônia do Sacramento.

A conturbada história da Colônia, principalmente depois de 1735, apresenta características específicas que a aproximam do cotidiano vivido pelos habitantes das praças-fortes portuguesas na Índia e no Marrocos, pois lá, como no Rio da Prata, as feitorias e cidades fortificadas, que inicialmente se destinavam a controlar e proteger o comércio, não conseguiram expandir seu domínio pelo interior, onde encontraram forte oposição dos sultões e imperadores muçulmanos e, a partir de fins do século XVII na Índia, da temida confederação Marata. ${ }^{73}$ Capistrano de Abreu não deixou de traçar um paralelo entre as experiências colonizadoras dos portugueses no Prata e no Oriente, ao enaltecer a figura do governador Antônio Pedro de Vasconcelos durante o cerco promovido pelos espanhóis, comentando que o mesmo "resistiu com um esforço e heroísmo que lembra algumas das mais belas páginas da história portuguesa na Índia". ${ }^{74}$

Heroísmo e fidelidade, mas também deserção, desespero e fome, foram sentimentos que marcaram a vida dos habitantes da Colônia, esse pequeno povoado onde a rede de tensões cotidianas não se restringia aos atritos intraclasses dos moradores, mas incluía as dificuldades de relacionamento com os habitantes dos arredores, os indígenas minuanos, charruas e guaranis e principalmente com os espanhóis, inimigos tradicionais dos portugueses. Essas características do cotidiano em Sacramento faziam com que o povoado fosse um temido local de degredo, imagem que os raros períodos de paz e a fertilidade da terra conseguiram apagar por alguns momentos.

\section{Notas}

${ }^{1}$ CANABRAVA, Alice Piffer. O comércio português no Rio da Prata (1580-1640). Belo Horizonte: Itatiaia; São Paulo: Edusp, 1984.

${ }^{2}$ RODRÍGUEZ, Mauro. Dom Pedro of Braganza and Colônia do Sacramento, 1680-1705. Hispanic American Historical Review, Durham, vol. XXXVIII, no 2, p. 187-188, May, 1958.

3 "Banda Oriental" era o nome dado pelos espanhóis ao território situado na margem leste do rio Uruguai, região hoje dividida pela República Oriental do Uruguai e pelo estado do Rio Grande do Sul.

${ }^{4}$ Consulta do Conselho Ultramarino de 21 de janeiro de 1726. IHGB, Arq. 1.1.21, f. 344v-346.

${ }^{5}$ Registro de uma carta régia dirigida ao governador do Rio de Janeiro, 4 de março de 1718. In: Anais da Biblioteca Nacional do Rio de Janeiro, vol. XXXIX. p. 369-370.

${ }^{6}$ Campaña del Brasil. Buenos Aires: Archivo General de la Nación, 1931. p. 452-453.

${ }^{7}$ Idem, p. 453-457.

${ }^{8}$ MONTEIRO, Jonathas da Costa Rego. A Colônia do Sacramento (1680-1777). Porto Alegre: Globo, 1937, v. 2, p. 58-59.

${ }^{9}$ CORTESÃO, Jaime. Alexandre de Gusmão e o Tratado de Madrid. Rio de Janeiro: Instituto Rio Branco, 1950, parte I, tomo II. p. 59-63.

${ }^{10}$ Idem, p. 63-66.

${ }^{11}$ Idem, p. 64.

${ }^{12}$ Campaña del Brasil. Op. cit., p. 501.

${ }^{13}$ Manuscritos da Coleção de Angelis. Tratado de Madrid - Antecedentes: Colônia do Sacramento (1669-1749). Rio de Janeiro: Instituto Rio Branco, 1954. p. 244-252.

${ }^{14}$ LISANTI, Luís (Org.) Negócios Coloniais. Brasília: Ministério da Fazenda; São Paulo: Visão Editorial, 1973, vol. 4, p. 376-377.

${ }^{15}$ SYLVA, Silvestre Ferreira da. Relação do Sítio da Nova Colônia do Sacramento. Porto Alegre: Arcano 17, 1993. p. $28-31$.

${ }^{16}$ Campaña del Brasil. Op. cit., 1931. p. 505. 
${ }^{17}$ Noticia Práctica del sitio de la Nueva Colonia del Sacramento y demás operaciones de los enemigos desde el mes de septiembre hasta el 18 de diciembre de 1735, siendo Gobernador de aquella Plaza Antonio Pedro de Vasconcellos. Revista Histórica, Montevideo, 1916, tomo VII, no. 22. p. 607-608.

${ }^{18}$ CORTESÃO, Jaime Cortesão. Op. cit., p. 68-69.

${ }^{19}$ LISANTI, Luís (Org.). Op. cit., vol. 4, p. 385.

${ }^{20}$ SYLVA, Silvestre Ferreira da. Op. cit., p. 41.

21 "Sistema entre un Portuguez y un jenobes dentro de la colonia del Sacramiento hablaron sobre el lamentable estado de ella y sus moradores...”. Archivo Regional de Colonia. Reg. 217, 38, T5, doc. 4, f. 35-36.

${ }^{22}$ Idem, f. 36.

23 "Noticia Práctica del sitio de la Nueva Colonia del Sacramento...". Op. cit., p. 606-607.

${ }^{24}$ RIVEROS TULA, Anibal M. Historia de la Colonia del Sacramento, 1680-1830. Apartado de la Revista del Instituto Histórico y Geográfico del Uruguay, Montevideo, tomo XXII, 1959, p. 169-170.

25 “Certificados referentes a los servicios y méritos funcionales de Caetano de Couto Vellozo...”. Archivo Regional de Colonia. Reg. 217, 38 T5, doc. 3, f. 23.

${ }^{26}$ SYLVA, Silvestre Ferreira da. Op. cit., p 84.

27 "Já era uma convenção da guerra de assédio que a recusa de se render, depois de aberta uma brecha, eximia os atacantes da obrigação de oferecer mercê ou se abster de saquear. $\mathrm{Na}$ era da artilharia essa convenção tornou-se absoluta”. KEEGAN, John. Uma história da guerra. São Paulo: Companhia das Letras, 1995. p. 333.

${ }^{28}$ SYLVA, Silvestre Ferreira da. Op. cit., p. 90.

29 "A primeira expedição de socorro, sob o comando do sargento-mor Tomás Gomes da Silva, deixou o Rio em 15 de dezembro de 1735. Compunha-se de seis embarcações e levava trezentos e sessenta marinheiros, duzentos e cinquenta infantes, quarenta e dois Dragóes das tropas de Minas Gerais e trinta e cinco artilheiros. Ao lado dos militares seguiam ainda oitenta e seis prisioneiros e vinte e cinco índios, o que sugere que o sistema de recrutamento compulsório aplicado à população masculina do Rio foi insuficiente para completar o número de soldados necessários, tendo-se de recorrer aos prisioneiros. $\mathrm{Na}$ Bahia, o vice-rei, conde de Galveias, tratou de organizar uma expedição de socorro que saiu de Salvador, a bordo de dois navios, em 31 de dezembro de 1735. Compunha-se de um destacamento de duzentos soldados, retirados dos dois Terços que guarneciam a cidade, aos quais se acrescentaram três capitães de infantaria e um de artilharia, três alferes, seis sargentos e cinquenta artilheiros. Os reforços foram divididos em quatro companhias: duas de sessenta soldados cada e uma de oitenta, enquanto outra reunia os cinquenta artilheiros." POSSAMAI, Paulo. A vida quotidiana na Colônia do Sacramento. Lisboa: Livros do Brasil, 2006. p. 179.

${ }^{30}$ MONTEIRO, Jonathas da Costa Rego. Op. cit., p. 231-242.

${ }^{31}$ SÁ, Simão Pereira de Sá. História Topográfica e Bélica da Nova Colônia do Sacramento do Rio da Prata. Porto Alegre: Arcano 17, 1993. p. 96.

${ }^{32}$ Idem, p. 110.

${ }^{33}$ LISANTI, Luís (Org.). Op. cit., vol. 4, p. 395.

${ }^{34}$ Idem.

35 Idem.

${ }^{36}$ Idem.

${ }^{37}$ SÁ, Simão Pereira de. Op. cit., p. 75.

38 “Certificados referentes a los servicios y méritos funcionales de Caetano de Couto Vellozo...”. Archivo Regional de Colonia. Reg. 217, 38 T5, doc. 3, f. 20-27.

39 SYLVA, Silvestre Ferreira da Silva. Op. cit., p. 51-66.

${ }^{40}$ SÁ, Simão Pereira de. Op. cit., p. 79.

${ }^{41}$ SYLVA, Silvestre Ferreira da. Op. cit., p. 72-75.

42 " $Y$ cuando se hizo de nuestra parte llamada, se alegro mucho la gente, y lo tenian a milagro, deseando se concluyesen los ajustes, y viendo, que no se convenían los Gobernadores, se alborotaron amagando, que se pasarían a nuestro Campo; que para aquietarlos, les dijo su Gobernador Portugues, que el Gobernador de Buenos-Ayres, los quería llevar a todos prisioneros, y que a los Mulatos de la Bahia, los harían esclavos; que al oir esto dijeron, que querían pelear hasta morir". Cf. Relación del sitio, toma, y desalojo de La Colonia, nombrada el Sacramento, en que se hallaban los Portugueses desde el año 1680 em el Rio de La Plata a vista de las Islas de S. Gabriel'. Revista del Instituto Histórico y Geográfico del Uruguay, Montevidéu, 1928, tomo VI, no. 1 p. 205.

43 "A este tempo, em que a guarnição estava entrada na estação do mais rigoroso frio, que é naquele país nos meses de maio até setembro, começaram os soldados dos destacamentos, proximamente vindos, a experimentar a falta dos ares pátrios, 
perdendo inteiramente a saúde, naqueles que por frigidíssimos se lhe mostravam estranhos; por cujo motivo picavam já as doenças a toda a guarnição, sem as poder reparar remédio algum”. SYLVA, Silvestre Ferreira da. Op. cit., p. 95.

${ }^{44}$ Idem, p. 96.

${ }^{4}$ SÁ, Simão Pereira de. Op. cit., p. 105.

${ }^{46}$ Idem, p. 107.

${ }^{47}$ BARRETO, Abeillard. A Expedição de Silva Pais e o Rio Grande de São Pedro. In: História Naval Brasileira, Rio de Janeiro: Ministério da Marinha, Serviço de Documentação Geral da Marinha, 1975, vol. 2, tomo 2. p. 9-17.

${ }^{48}$ Gomes Freire chegou ao Rio em 20 de maio de 1736; de lá manteve intensa correspondência com Martinho Mendonça, a cujo cargo ficara o governo interino de Minas Gerais. Cf. Carta de Gomes Freire a Martinho de Mendonça, 21 de maio de 1736. Revista do Archivo Publico Mineiro, vol. II. p. 239.

${ }^{49}$ BARRETO, Abeillard. Op. cit., p. 12-16.

${ }^{50}$ Carta de Abreu Prego a Gomes Freire, 4 de Janeiro de 1737. Revista do IHGRS, no. 104, p. 349.

${ }^{51}$ Carta de Vasconcelos a Abreu Prego, 11 de fevereiro de 1737. Revista do IHGRS, no. 99, p. 87.

${ }^{52}$ Carta de Silva Pais a Gomes Freire, 4 de janeiro de 1737. Revista do IHGRS, no .104, p. 393.

${ }^{53}$ Registro de uma proposta do comissário da expedição a Silva Pais, 11 de novembro de 1736. Anais do Arquivo Histórico do Rio Grande do Sul, vol. 1, p. 37.

54 "Registro de hum bando sobre darsse guerra ao gentio ou indios q. estão agregados ao castilhano por estes fazerem operação a povoação da Collonia e o mais que nelle se declara \&a”. Revista do Arquivo Municipal. São Paulo, 1939, vol. LXI, p. $131-132$.

55 “Sistema entre un Portuguez y un jenobes...”. Archivo Regional de Colonia. Reg. 217, T5, doc. 4, f. 38.

56 "Carta de Cristóvão Pereira de Abreu, para Gomes Fr. ' de Andrada, datada do Rio Grande em 2 de Novembro de 1736". In: ALVES, Artur da Motta (comp.). Documentos sobre a Colônia do Sacramento e o Rio Grande de São Pedro. Revista do IHGRS, Porto Alegre, IV trimestre de 1946, nº. 104, p. 360.

57 "Carta do Brigadeiro Jose da Silva Paes, datada de 24 de Setembro de 1736, para o Gn. 'Gomes Freire de Andrada". In: ALVES, Artur da Motta (comp.). Op. cit., p. 388.

${ }^{58}$ Registro da Provisão que fizeram os casais vindos de Colonia. Rio de Janeiro, 10 de dezembro de 1736. ANRJ. cód. 60, vol. 20, f. 146.

${ }^{59}$ Idem, f. $146 \mathrm{v}$.

${ }^{60}$ LISANTI, Luís (Org.). Op. cit., vol. 3, p. 617-618.

${ }^{61}$ Memória dos serviços prestados pelo mestre de campo André Ribeiro Coutinho (1740). In: "Inventário de Castro e Almeida". Anais da Biblioteca Nacional, Rio de Janeiro, 1936, vol. L, doc. n. ${ }^{\circ} 16.839$, p. 328.

${ }^{62}$ MONTEIRO, Jonathas da Costa Rego. Op. cit., vol. 1, p. 331.

${ }^{63}$ RIVEROS TULA, Anibal M. Op. cit., p. 149.

${ }^{64}$ Carta de Martinho de Mendonça para Gomes Freire, 26/12/1736. Revista do Archivo Publico Mineiro, Belo Horizonte, 1911, p. 372.

${ }^{65}$ Carta de Martinho de Mendonça a Gomes Freire de Andrade, 18 de julho de 1737. Revista do Arquivo Público Mineiro, vol. II, p. 446.

${ }^{66}$ BOXER, C. R. A mulher na expansão ultramarina ibérica. Lisboa: Horizonte, 1977. p. 33

${ }^{67}$ Apud BARROS-LÉMEZ, Alvaro. V Centenario en el Río de la Plata. Montevidéu: Monte Sexto, 1992, p. 76.

${ }^{68}$ FARINHA, António Dias. História de Mazagão durante o Periodo Filipino. Lisboa: Centro de Estudos Históricos Ultramarinos, 1970, p. 67.

${ }^{69}$ MILLAU, Francisco. Descripción de la Provincia del Río de la Plata. Buenos Aires: Espasa - Calpe, 1947, p. 112.

${ }^{70}$ FARINHA, António Dias. Op. cit., p. 55.

${ }^{71}$ Apud BARROS-LÉMEZ, Alvaro. Op. cit., p. 76. No original: "A mí me parece que los Portugueses viven tan estrechados y son mantenidos por los Españoles tan entre barreras como actualmente los judíos en nuestros países. Yo mismo he visto los centinelas en derredor de la ciudad; me pareció como si la ciudad estuviere bloqueada de continuo. No es posible que desde el lado de la tierra pueda colarse alguna cosa si - bien entendido - los centinelas no son pillos e intermediarios. Yo no sé si tal cosa ocurre pero es probable sea así". Tradução do editor.

72 PRADO, Fabrício. A Colônia do Sacramento, o extremo sul da América portuguesa. Porto Alegre: F. P. Prado, 2002. p. 53.

${ }^{73}$ ROSSA, Walter. Cidades Indo-Portuguesas. Lisboa: Comissão Nacional para as Comemoraçôes dos Descobrimentos Portugueses, 1997. p. 96-97.

${ }^{74}$ CAPISTRANO DE ABREU, João. Sobre a Colônia do Sacramento. In: SÁ, Simão Pereira de. Historia Topographica e Bellica da Nova Colonia do Sacramento do Rio da Prata. Rio de Janeiro: Leuzinger, 1900. p. XXVIII. 


\section{Referências bibliográficas}

\section{Fontes impressas}

BARROS-LÉMEZ, Álvaro (comp.). V Centenario en el Río de la Plata: Pioneros, Adelantados, Caminantes, Fundadores. 2.ed. Montevidéu: Monte Sexto, 1992.

Campaña del Brasil - Antecedentes Coloniales. Documentos referentes a la guerra de la independencia y emancipación política de la República Argentina y de otras secciones de América. Segunda série, dirigida por Carlos Correa Luna. Buenos Aires: Archivo General de la Nación, 1931. Tomo 1 (1535-1749).

Documentos avulsos sobre a Colônia do Sacramento publicados pelos Anais do Arquivo Histórico do Rio Grande do Sul. Porto Alegre: Instituto Estadual do Livro, 1977. Vol. 1.

Documentos sobre a Colônia do Sacramento. Revista do Instituto Histórico e Geográfico do Rio Grande do Sul. Porto Alegre, no. 99, p. 41-117, III trim. de 1945.

Documentos sobre a Colônia do Sacramento e o Rio Grande de São Pedro. Revista do Instituto Histórico e Geográfico do Rio Grande do Sul. Porto Alegre, no. 104, p. 337-475, IV trim. de 1946.

Manuscritos da Coleção De Angelis: Tratado de Madrid - Antecedentes: Colônia do Sacramento (1669-1749). Introdução, notas e sumários por Jaime Cortesão. Rio de Janeiro: Biblioteca Nacional, 1954.

MILlaU, Francisco. Descripción de la Provincia del Río de la Plata [1772]. Buenos Aires: Espasa - Calpe, 1947.

Noticia práctica del sitio de la Nueva Colonia del Sacramento y demás operaciones de los enemigos desde el mes de septiembre hasta el 18 de diciembre de 1735, siendo Gobernador de aquella Plaza Antonio Pedro de Vasconcellos. Revista Histórica, Montevideo, tomo VII, no 22, p. 604-616, 1916.

LISANTI, Luís (Org.). Negócios Coloniais (uma correspondência comercial do século XVIII). Brasília: Ministério da Fazenda; São Paulo: Visão Editorial, 1973.

Relación del Sitio, toma y desalojo de la Colonia nombrada del Sacramento, en que se hallaban los Portugueses desde el año 1680, en el Río de la Plata a vista de las islas de S. Gabriel. Revista del Instituto Histórico y Geográfico del Uruguay, Montevideo, tomo VI, no 1, p. 197-206, 1928.

SÁ, Simão Pereira de. História topográfica e bélica da nova Colônia do Sacramento do Rio da Prata [1737]. Porto Alegre: Arcano 17, 1993.

SYLVA, Silvestre Ferreira da. Relação do Sitio da Nova Colônia do Sacramento. Fac-símile da edição de 1748. Porto Alegre: Arcano 17, 1993.

\section{Referências bibliográficas}

ALMEIDA, Luís Ferrand de. A Colônia do Sacramento na época da sucessão de Espanha. Coimbra: Faculdade de Letras da Universidade de Coimbra, 1973.

BARRETO, Abeillard. A expedição de Silva Pais e o Rio Grande de São Pedro. In: et alii. História Naval Brasileira. Rio de Janeiro: Ministério da Marinha, Serviço de Documentação Geral da Marinha, 1975, vol. 2, tomo 2, p. 9-54.

BOXER, C. R. A mulher na expansão ultramarina ibérica. Lisboa: Horizonte, 1977.

CANABRAVA, Alice Piffer. O comércio português no Rio da Prata (1580-1640). Belo Horizonte: Itatiaia; São Paulo: EDUSP, 1984.

CORTESÃO, Jaime. Alexandre de Gusmão e o Tratado de Madrid. Rio de Janeiro: Instituto Rio Branco, 1950.

FARINHA, António Dias. História de Mazagão durante o Periodo Filipino. Lisboa: Centro de Estudos Históricos Ultramarinos, 1970.

KEEGAN, John. Uma história da guerra. São Paulo: Companhia das Letras, 1995.

MONTEIRO, Jonathas da Costa Rego. A Colônia do Sacramento (1680-1777). Porto Alegre: Globo, 1937.

POSSAMAI, Paulo. A vida quotidiana na Colônia do Sacramento. Lisboa: Livros do Brasil, 2006.

PRADO, Fabrício. A Colônia do Sacramento. O extremo sul da América portuguesa. Porto Alegre: F. P. Prado, 2002. 
RIVEROS TULA, Anibal M. Historia de la Colonia del Sacramento, 1680-1830. Apartado de la Revista del Instituto Histórico y Geográfico del Uruguay. Montevideo, tomo XXII, 1959.

RODRÍGUEZ, Mario. Dom Pedro of Braganza and Colônia do Sacramento, 1680-1705. Hispanic American Historical Review. Durham, vol. XXXVIII, nº. 2, p. 179-208, May, 1958.

ROSSA, Walter. Cidades Indo-Portuguesas. Lisboa: Comissão Nacional para as Comemorações dos Descobrimentos Portugueses, 1997.

\title{
RESUMO
}

Fundada em 1680, quando a Coroa portuguesa buscava expandir seus dominios na América, a Colônia do Sacramento passou de um pequeno entreposto fortificado a um importante núcleo comercial e de povoamento no início do século XVIII. Entretanto, o cerco espanhol, que se estendeu de 1735 a 1737, limitou seu caráter de centro povoador e núcleo de expansão portuguesa no Rio da Prata a um papel exclusivamente comercial e militar. O levantamento do cerco, em 1737, não implicou o abandono do bloqueio à praça, que continuou até a sua entrega definitiva à Coroa espanhola, em 1777. Procuramos, neste artigo, estabelecer um paralelo entre o cotidiano da população da Colônia do Sacramento, durante o tempo que em viveu sob o bloqueio espanhol, e o dos habitantes das praças fortes portuguesas no Marrocos e na India, onde a população vivia sob o constante controle de seus movimentos e de ameaças de invasão por parte dos inimigos.

Palavras-chave: povoamento; guerra; cotidiano; Colônia do Sacramento; século XVIII.

\begin{abstract}
Founded in 1680, when the Portuguese Crown was trying to expand its possessions in America, Colonia do Sacramento grew from a small fortified market to a major center of trade and settlement in the early eighteenth century. However, the Spanish siege that lasted from 1735 to 1737 limited its character of settlement center and core of the Portuguese expansion in the Rio de la Plata to an exclusively commercial and military role. The lifting of the siege in 1737 did not imply the abandonment of the blockade on the fortification, which continued until its final delivery to the Spanish Crown in 1777. This article has tried to point out similarities between the daily life of the population of Colonia do Sacramento during the period when they lived under the Spanish blockade, and the daily life of the inhabitants of the Portuguese strongholds in Morocco and India, where the population lived under constant control and under threats of enemy invasion.
\end{abstract}

Keywords: settlement; war; daily life; Colony of Sacramento; eighteenth century. 